\title{
Distance is a barrier to recycling - or is it? Surprises from a clean test
}

\author{
Changjun Li ${ }^{a}$, Yi Zhang ${ }^{a}$, Pierre Nouvellet ${ }^{b}$, Joseph O. Okoro ${ }^{a}$, Wang Xiao ${ }^{a}$, \\ Marie K. Harder ${ }^{\mathrm{a}, \mathrm{c}^{*}}$
}

${ }^{a}$ Department of Environmental Science \& Engineering, Fudan University, 2005 Songhu Road, Shanghai 200438, PR China

${ }^{\mathrm{b}}$ University of Sussex, Falmer, Brighton, BN1 9RH, United Kingdom

${ }^{c}$ University of Brighton, Cockcroft Building, Lewes Road, Brighton, BN2 4GJ, United Kingdom

* Corresponding author:

Email-address: M.K.Harder@Brighton.ac.uk

Department of Environmental Science \& Engineering, Fudan University, 2005 Songhu Road, Shanghai 200438, PR China 


\begin{abstract}
The distance of recycling bins from households is often considered important by practitioners, but published evidence for this uses only indirect and self-reported data. This study aims to provide such evidence by obtaining a clean test using measured distances in a walled community with 1200 households with the same building types, local governance, recycling and waste arrangements. The number of deposits each month of food waste for recycling at a designated site are logged via smart-cards allocated per household. The number of days per month that each household deposits showed a highly significant - but small - negative correlation with distance of the bin: fewer householders participate if further away, accounting for 3\% of the variation. Surprisingly, there is no variation with distance among those who do participate: their recycling frequency does not vary. This second result is not consistent with the first in terms of cost/benefit concepts assumed by government planners, nor with the static theories of behaviour currently used in waste management research. We recommend that recycling practitioners note the smallness of the contribution of distance to recycling performance, and not overrate it. And we recommend that researchers make better use of non-static models (which model different stages towards behaviour change), which our second result appears to call for.
\end{abstract}

Keywords: recycling; behaviour change; inconvenience; change theory 


\section{Introduction}

Municipal solid waste (MSW) is a global issue, due both to its large and growing quantity and the difficulties associated with its treatment and disposal. In China, 191 million tons of MSW were reported to have been collected in 2015, to sanitary landfills (63.7\%) and incineration (34.3\%), with biological processes such as composting and anaerobic digestion constituting only $2.0 \%$ of the total (State Statistical Bureau, 2015). Policies encouraging circular economies have slowly increased value chains to divert some industrial wastes back into production cycles, but this has proven much more challenging for residential waste (IPCC, 2014). This is because the value of recyclable materials in the residential waste is very low unless they are separated at source - in the home. The China government started pilot residential waste-sorting programs in forty-six cities in 2017 (General Office of the State Council, 2017). Those cities were expected to build a complete city solution, covering collection, transportation, disposal, and relevant laws, regulations and standards by the end of 2020 . The target was for a recovery rate of $35 \%$ for 'dry' recyclables (paper, card, plastic bottles) and food waste, combined.

Shanghai and Nanjing Municipalities have experimented previously for several years with small-scale pilot programs that can successfully get residents to separate their food waste to high standards (Huang et al., 2014). Since the cities are organised into thousands of walled residential communities, these provide self-contained opportunities to study the influence of various factors. One factor of interest is the distance of the communal waste station(s), where the recycling bins are, from the apartment building entrances. Government planners worldwide commonly use a simple 'rational actor' approach (Jackson, 2005), assuming the actions of residents are decided only after weighing up perceived costs and benefits. This would imply that the further the distance for recycling, the less likely that residents would participate, or participate frequently. However, providing more waste stations within communities is costly both financially and in terms of labour for collection and cleaning: it would thus be preferable to have evidence to back up the assumptions, or to confirm them 
with field experiments.

In this work we carry out field experiments to provide evidence of the strength of influence of the distance of recycling bins on recycling participation, and frequency. This information is needed to input into plans for mega-city programs for residential waste-sorting, to guide the number of bins and bin 'stations' needed for a balance of bin costs versus recycling performance. Section 2 summarises the findings from literature and their limitations; Section 3 sets out our methods of data collection for direct measures; Section 4 presents results and statistical analyses, and Section 5 discusses the relevance of the results and their inconsistency with respect to cost/ benefit concepts.

\section{Literature review}

We carried out, and summarize in Table 1, a systematic review of peer-reviewed published journal articles on recycling within 1990-2018 which investigated distance. We found none directly investigated distance, although some did refer to distance when mentioning 'inconvenience', either as an undefined term offered by residents in open questions, or as part of a psychology-based construct. Our systematic review covered papers from 1990 to 2018 inclusive which refer to 'inconvenience' or 'distance' as potential determinants of any measured recycling performance indicator (including further works referenced therein), using Web of Science, with full search terms of: waste AND (recycling OR composting OR "source sorting") AND (determinants OR factors OR variables) AND (household OR residential OR domestic OR municipal OR curbside OR kerbside OR MSW)

[Insert TABLE 1 about here]

In practice-based field studies, householders use the term 'inconvenience' to variously imply many things, including distance to the depositing site, availability of relevant facilities; in-house storage space for sorted wastes; and the time required (Tonglet et al., 2004). Other studies mention inconvenience without distance, e.g. 
concerning lack of space for recycling bins (Seonaidh and Caroline, 2003). One reason for the lack of standard definitions which allow easy operationalisation in the field is that, in reality, 'rational actor costs' are not straightforward as they are a mixture of situational and psychological factors. Theories need more simple starting points and fewer parameters than real situations (Jackson 2005), but they simplify the situation differently, introducing multiple varieties of conceptual constructs (Jackson, 2005 ) which unfortunately each relate to operationalizable, measurable, factors in different ways - and often only indirectly. For example, Blake's Value Action Gap (1999) model sets out individuality (e.g. laziness), responsibility (e.g. not my job) and practicality (e.g. not enough time) as constructs of possible barriers even when personal values are conducive to recycling - and all of these are complex to operationalise, for example compared to factors like some types of incentives, the number of materials collected, and interpersonal interaction (Harder et al., 2007; Woodard et al., 2006; Dai et al., 2016). This makes such theories less useful for recycling practitioners in their planning, and even researchers use them for retrospective descriptions rather than predictions.

Another difficulty is that psychology-based studies have identified residents' attitudes or intentions as main factors for recycling (Barr et al., 2003; Hage et al., 2009; Tonglet et al., 2004), but a gap between attitudes and actual behaviour is commonly reported (Blake, 1999; Jackson, 2005; Kollmuss, 2002). These unpredictable gaps between theoretical constructs and measurable practice also makes theories less useful for planning recycling programmes.

Lastly, we found that all of the studies involving distance identified in our systematic review, including via indirect mention within 'inconvenience', obtained their data through self-report rather than measurement. This is possibly due to the relatively low manpower cost. For transparency we note that two of them suggested correlations with distance. One found that recycling participation rates were negatively related to (reported) distance from communal bins, using street interviews (González-Torre and Adenso-Díaz, 2005), and another suggested, from survey results, that the (self- 
reported, qualitatively commented) distance and ease of access to drop-off points could be a main motivator for recycling behaviours (PCAESG and Group, 1999). However, the usefulness of such self-reported results has been criticized, as inconsistencies are found between self-reported and actual behaviours in waste recycling (Perrin and Barton, 2001; Williams and Kelly, 2003).

Overall, we learned from our literature review that there were no studies which could assist us with our real-world problem of: how to advise city planners of mega-cities in China as to the advantages and disadvantages of providing recycling bins either close to households (requiring more of them), or further away (potentially reducing recycling performance). There was thus a clear and current need to determine this information and this is the aim of this study.

\section{Methodology and Method}

Our approach was designed to avoid the problems found in the literature: inconsistency between reported and direct measures; use of indirect or proxy measures, and use of theoretical constructs as key factors. We wished to provide a direct and clear data on the relationship between recycling and the distance walked. In this paper we present a study which uses direct measures of distance to the communal recycling bins, and direct measures of resident participation rates and frequency rates, to test for correlations. We proposed the following hypotheses: H1: the farther the Distance, the lesser the participation rate.

$\mathrm{H} 2$ : the farther the Distance, the lesser the participating frequency. Our study takes advantage of China's urban residential arrangements which offer unique advantages in researching recycling behaviours, because in those cities typical residential communities are organized in housing compounds, informally gated and walled, with communal gardens and parking areas between the buildings. Usually, 100-1500 households live in apartment buildings in one community with central waste depositing bins and one informal governance committee, which can thus serve as a very convenient experimental unit for recycling research (Dai et al., 2015). 


\subsection{Site}

The site chosen is one within a waste recycling scheme in the city of Nanjing, where all households have been issued smart cards which are used to receive electronic points when separated food waste is brought to a central communal collection point, (recycling station), available daily. The points can be exchanged for small goods or services each month, such as a bag of salt or knife-sharpening. The unit of assessment is 'groups of households' on a given floor F of a given building. There are 1200 households in 34 buildings of 4-6 floors, situated within a range of 80 to 360 metres (mean of $180 \mathrm{~m}$, standard deviation $=73 \mathrm{~m})$ from the recycling station. Each recycler has to walk over a well-defined flat distance, $\mathrm{D}$, along paths to reach the deposit bins. Additionally, some people have to first walk down (F-1) flights of stairs (there are no elevators), where $\mathrm{F}$ denotes the floor level with the ground floor as $\mathrm{F}=1$. The Community was nominated to us by the local government as being typical of this 'Street' (ward), and we confirmed that the participation rate, demographic characteristics, types of buildings and compound layout of this Community are similar with the other 22 communities in the same 'Street' (ward). This means that our results are likely to be transferable to many other communities. We give the demographic characteristics of the Community in Table 2.

[Insert TABLE 2 about here]

\subsection{Measures}

Participation Rates (PR) and the frequency of participation (ND, the Number of Days of participation in a given month), are used to measure waste sorting performance. (The days occurred in August, which was a convenience choice that we note here only for reference.) These indicators are standard ones used in other waste studies (Dahlén, 2005; DETR, 1999; Roddick, 1997), in this case applied to each group of households on the same floor (F) of the same building a set distance (D) from the bins. (Although our data is available daily, we have analysed it by month to 
be consistent with those standard indicators. We also provide the more-detailed raw household data in an accessible dataset (Harder, 2018) which includes the exact number of days, ND, of participation for each household, in case it is useful to researchers for other purposes.)

We thus calculate the Participation Rate, PR as:

$\mathrm{PR}=\mathrm{PH} / \mathrm{TH}(M=0.28, S D=0.18)$

Where

$\mathrm{PR}=$ Participation Rate (within one month)

$\mathrm{PH}=$ number of Participating Households in a given building (which has a set D, F set) (with a set threshold frequency of at least one day* within one month)

$\mathrm{TH}=$ the Total number of Households in a given D,F set

$\mathrm{D}, \mathrm{F}=$ the distance $\mathrm{D}$ of the building away from the recycling bins, and the floor number $\mathrm{F}$ of the households in that set i.e. $1^{\text {st }}$ floor, $2^{\text {nd }}$ floor.

\subsection{Analysis method and process}

The data analysis was conducted with RStudio and Statistical Product and Service Solutions (SPSS). We applied a binomial logistic regression of the proportion of households recycling (PR) against:

- the Distance to the waste-station only (Model 1)

- both the Distance to the waste-station and the Floor level (Model 2)

In Model 1, we tested whether PR decreases/increases with Distance. In Model 2, we tested whether PR decreases/increases with either or both Distance and Floor. Then we compared Model 1 and Model 2 by ANOVA (chi-square test) and obtained the pseudo $\mathrm{R}^{2}$ (McFadden, 1979) to analyze the variance in recycling behaviour explained by Distance.

We also tested whether ND decreases/increases with Distance by linear regression.

\section{Results}

4.1 Results of binomial logistic regression: PR against Distance only (Model 1) 
The statistical analysis for Model 1 indicated that the number of households recycling was significantly correlated to the Distance. More precisely, the Distance (of the building from the recycling bins) was predictive of the proportion of households (in that building) recycling: the farther away the building, the lesser the recycling (see Table 3).

[Insert TABLE 3 about here]

\subsection{Results of binomial logistic regression: PR against Distance and Floor (Model 2)}

As shown in Table 4, the outcome of Model 2 indicated that only Distance predicted the proportion of households recycling $(P R)(p<0.01)$, while Floor did not.

[Insert TABLE 4 about here]

\subsection{Results of ANOVA test between Model 1 and Model 2}

The ANOVA test result confirmed that Model 2 (including 'Floor' and 'Distance' as predictors), rather than Model 1 (with only 'Distance' as predictor), was not statistically justified $\left(\chi^{2}=7.13, \mathrm{p}=0.21>0.05\right)$. However, there is low predictive ability, with Distance accounting for only $3 \%$ of the variance in $P R, d f=5, N=197$, Odd Ratios $=0.77$. The primary dataset has been made (Harder, 2018).

Because the Floor has no correlation with the PR, we moved to using the building as the unit of assessment (containing several households). The scatterplot of PRs for each building were plotted against the relative Distances from the recycling station, shown in Fig. 1.

[Insert FIGURE 1 about here]

\subsection{Results of linear regression: ND against Distance}

The scatterplot of ND for each building were plotted against the relative Distances from the waste-station, and the results are shown in Fig. 2. We did not find a correlation between Distance and ND by linear regression $(p=0.63>0.05)$. This result is not consistent with most cost/benefit models or static behaviour theories 
(Vencatasawmy et al., 2000; Sidique et al., 2010). In other words, for those currently participating, the Distance away from the deposit bins was not a factor. This is an interesting result, because it appears to be inconsistent with the result of $\mathrm{H} 1$ when interpreted through the current explanations of cost and benefit, which would predict that increasing Distance should reduce recycling frequency, and thus a negative correlation. The fact that this explanation does not fit our both sets of our experimental results, i.e. for both $\mathrm{H} 1$ and $\mathrm{H} 2$, indicates that a new explanation and understanding should be considered.

[Insert FIGURE 2 about here]

\section{Discussion}

In this study, clean and reliable data from a long-term, medium size pilot scale project were utilized to conduct a quantitative analysis on residential food waste sorting behaviour in 1200 China urban households in a residential community in Nanjing, with special focus on Distance (to the recycling station), and Floor level in buildings without elevators. By 'clean' we mean the main variables of Distance and recycling performance were precisely known, i.e. they were not folded in with other variables or extracted from a construct. (A caveat is that the motivation to begin recycling, 11 months earlier, might have been the incentives offered, and even though we know the motivation of the nature has changed over time, this background information should be considered by researchers using our findings.) Results indicate a highly significant correlation of participation rate PR with distance D: fewer households participate the further away they are. This result is consistent with rational actor theory (Jackson, 2005), and a common assumption of city planners, providing strong evidence not previously published. However, only $3 \%$ of the variation was accounted for in this way, suggesting the effect is very small, and hardly worth factoring in, much less emphasising.

No correlation was found for Floor levels. This result could have been argued either way: that the extra Floors walked down did/did not cause the residents extra effort and 
thus may/may not have decreased participation rates. On the one hand the distance was further: on the other hand the residents had to take all the waste downstairs anyway. Thus, although the data gives a clear result (non-correlation) useful for planning, it cannot elucidate the underlying reasons.

An unexpected additional result was also found: that a measure of recycling frequency (i.e. the Number of Days participated in a month, ND) did not vary with distance for those who were participating. This is inconsistent with current thinking about recycling behaviour in waste management literature which commonly assumes that any increase in required effort would reduce participation: that for the same benefit (credit points for recycling), fewer would be willing to pay an increased cost (i.e. walk further).

As this result was unexpected, interviews to investigate the underlying reasons behind it had not been planned. However, coincidentally, interviews were carried out in this Community for a different study in the same period, which concluded with the suggestion that the reasons stated for participation changed from an initial focus on incentives at the launch of the program, to references to personal habit, 11 months later ( $\mathrm{Li}$ et al. 2017). Our new data is consistent with the latter: Figure 2 shows that all of the residents currently participating are displaying characteristics of habit in that none participated less than 18 times that month - regardless of distance from the recycling station. It does seem plausible that for those with such a formed habit, the influence of distance might not come into play, and these results might stimulate further research to investigate links to theories. However, from a pragmatic point of view, as per the aim of this study, this result suggests that emphasis on forming habits in residents might pay off well compared to investment in extra numbers of recycling stations (at a lesser distance), as those will only slightly improve participation rates. The fact that our two results are inconsistent with each other from the point of view of any models currently used in waste management behaviour modelling, is worrying and interesting. These model static behaviour change, such as cost/benefit (Becker, 1976), The Theory of Planned behaviour (TPB)(Ajzen, 1988, 1991) or Theory of 
Interpersonal Behaviour (Li et al., 2017; Triandis, 1977). Of those, only the latter, Triandis model, allows the factoring in of habit at all - but still in a static mode. Thus, although our data does not explain whether the inconsistency is due to a shift over time - a difference in how the 'inconvenience' of the distance to the recycling station is viewed before, or after, developing a habit - it does seem that the use of a model which could allow for such shifts over time would work here, and also be consistent with the indicative results of the previous study (Li et al., 2017). Change models of behaviour change that could be considered in future work include the Rubicon Model of Action Phases (Heckhausen and Gollwitzer, 1987), the Transtheoretical Model (Prochaska and Di Clemente, 1986) and the Model of Self-regulated Behavioral Change (Bamberg, 2013).

\section{Conclusion}

This study is the first, that we know of, to directly investigate the relationship between distance to recycling bins, and participation rates and frequency. The results show clearly and cleanly that participation in a recycling scheme can be statistically significantly related to the distance to the recycling station, but that the effect and explained variance are small (3\%), and we recommend that researchers do not overrate it. No variation was seen by Floor level 1-6 of the households (which have no elevators).

Perhaps more importantly we also have shown that, at least in this case, and 11 months after the recycling program was launched, there is no variation with distance among those who do participate: the number of days in a month that they deposit recycling does not vary with distance. This second result is not consistent with the first in terms of cost/benefit concepts commonly used by government planners, indicating that current use of static-models of behaviour change may not be sufficient for understanding, and thus planning, programs. We thus recommend that researchers make better use of non-static models which can consider time-variant drivers for recycling. 


\section{Acknowledgements}

This study is supported by China Postdoctoral Science Foundation (No.

2018M632007) and China National Thousand Talents Programme. We would like to thank Wang Xiao for assistance with psychology approaches.

\section{References}

Ajzen, I., 1988. From intentions to actions: A theory of planned behaviour. In: J. Kuhl and Beckmann (Eds.). Action-Control: From cognition to behaviour. Springer, Heidelberg, Germany.

Ajzen, I., 1991. The Theory of Planned Behavior. Organ Behav Hum Decis Process. 50, 179-211.

Ando, A.W., Gosselin, A.Y., 2005. Recycling in multifamily dwellings: does convenience matter? Econo. Inq. 43, 426-438.

Baidu, 2018. Baidu Map. https://map.baidu.com/

Bamberg, S., 2013. Changing environmentally harmful behaviors: a stage model of self-regulated behavioral change. J. Environ. Psychol. 34, 151-159.

Barr, S., Ford, N.J., Gilg, A.W., 2003. Attitudes towards recycling household waste in Exeter, Devon: quantitative and qualitative approaches. Local Environ. 8, 407-421.

Barr, S., Gilg, A.W., 2005. Conceptualising and analysing household attitudes and actions to a growing environmental problem: Development and application of a framework to guide local waste policy. Appl. Geogr. 25, 226-247.

Barton, D.P.J., 2001. Issues associated with transforming household attitudes and opinions into materials recovery: a review of two kerbside recycling schemes. Resour. Conserv. Recycl. 33, 61-74.

Becker, G., 1976. The Economic Approach to Human Behaviour. University of Chicago Press, Chicago, USA.

Bernstad, A., la Cour Jansen, J., Aspegren, A., 2013. Door-stepping as a strategy for improved food waste recycling behaviour-Evaluation of a full-scale experiment. Resour. Conserv. Recycl. 73, 94-103.

Blake, J., 1999. Overcoming the , Aspe - action gap 1999. Overcoming the , Aspegren, A., 2013. Doorsteppolicy and local experience. Local Environ. 4, 257-278.

Brännström, C.P.V.M.Ö.T., 2000. A survey of recycling behaviour in households in Kiruna, Sweden. 13 Waste Manage. Res. 18, 545-556. 
Dahlén, L., 2005. To evaluate source sorting programs in household waste collection systems. Department of Civil and Environmental Engineering. Lulea University of Technology, Lulea, Sweden.

Dai, Y., Gordon, M., Ye, J., Xu, D., Lin, Z., Robinson, N., Woodard, R., Harder, M., 2015. Why doorstepping can increase household waste recycling. Resour. Conserv. Recycl. 102, 9-19.

Dai, Y., Lin, Z., Li, C., Xu, D., Huang, W., Harder, M., 2016. Information strategy failure: personal interaction success, in urban residential food waste segregation [J]. J. Clean. Prod. 134, 298-309.

DETR, 1999. Monitoring and evaluating recycling, composting and recovery programmes. HSMO, London, UK.

Gallardo, A., Bovea, M.D., Colomer, F.J., Prades, M., Carlos, M., 2010. Comparison of different collection systems for sorted household waste in Spain. Waste Manage. 30, 2430-2439.

Garcés, C., Lafuente, A., Pedraja, M., Rivera, P., 2002. Urban waste recycling behavior: antecedents of participation in a selective collection program. Environ. Manage. 30, 378-390.

General Office of the State Council, PRC, 2017. Notice of the general office of the state council on forwarding the implementation plan of the household waste sorting system of the ministry of housing and urban-rural development of the national development and reform commission. http://www.gov.cn/zhengce/content/2017-03/30/content_5182124.htm

González-Torre, P.L., Adenso-Díaz, B., 2005. Influence of Distance on the motivation and frequency of household recycling. Waste manage. 25, 15-23.

Hage, O., Söderholm, P., Berglund, C., 2009. Norms and economic motivation in household recycling: empirical evidence from Sweden. Resour. Conserv. Recycl. 53, 155-165.

Harder, M., Woodard, R., 2007. Systematic studies of shop and leisure voucher incentives for household recycling. Resour. Conserv. Recycl. 51, 732-753.

Harder, M., Stantzos, N., Woodard, R., 2008. Development of a new quality fair access best value performance indicator (BVPI) for recycling services. Waste Manage. 28, 299-309

Harder. M., 2018. "Supplementary Table S1 of "Distance is a barrier to recycling - or is it? Surprises from a clean test”, Mendeley Data, v2. http://dx.doi.org/10.17632/xdxg4f3zwg.2

Heckhausen, H., Gollwitzer, P.M., 1987. Thought contents and cognitive functioning in motivational versus volitional states of mind. Moti. Emot. 11, 101-120.

Huang, W., Wang, J., Dai, X., Li, M., Harder, M. K., 2014. More than financial investment is needed: 14 
food waste recycling pilots in Shanghai, China [J]. J. Clean. Prod. 67, 107-116.

IPCC, 2014: Summary for Policymakers. In: Climate Change 2014: Mitigation of Climate Change. Contribution of Working Group III to the Fifth Assessment Report of the Intergovernmental Panel on Climate Change [Edenhofer, O., R. Pichs-Madruga, Y. Sokona, E. Farahani, S. Kadner, K. Seyboth, A. Adler, I. Baum, S. Brunner, P. Eickemeier, B. Kriemann, J. Savolainen, S. Schlömer, C. von Stechow, T. Zwickel and J.C. Minx (eds.)]. Cambridge University Press, Cambridge, United Kingdom and New York, NY, USA. (10.4; 10.14 IPCC printed page, integrated with AFOLU figures Jackson, T., 2005. Motivating sustainable consumption: a review of evidence on consumer behaviour and behavioural change, Sustainable Development Research Network. Centre for Environmental Strategy, University of Surrey, GUILDFORD Surrey.

Kollmuss, A.A., J 2002. Mind the Gap. Environ. Educ. Res. 8, 239-260.

Li, C.J., 2017. A Study of Food Waste Sorting Behavior under an Economic Incentive Program in Nanjing. Fudan University, Shanghai, China.

Li, C.J., Huang, Y.Y., Harder, M.K., 2017. Incentives for food waste diversion: Exploration of a long term successful Chinese city residential scheme. J. Clean. Prod. 156, 491-499.

McFadden, D., 1979. Quantitative methods for analysing travel behavior of individuals: Some recent developments. In D. A. Hensher \& P. R. Stopher (Eds.), Behavioural travel modelling (pp. 279-318). London: Croom Helm.

Miliute-Plepiene, J., Hage, O., Plepys, A., Reipas, A., 2016. What motivates households recycling behaviour in recycling schemes of different maturity? Lessons from Lithuania and Sweden. Resour. Conserv. Recycl. 113, 40-52.

PCAESG, Group, P.C.A.a.E.S., 1999. Recycling used packaging form the domestic waste stream: Consumer awareness and education.

Perrin, D., Barton, J., 2001. Issues associated with transforming household attitudes and opinions into materials recovery: a review of two kerbside recycling schemes. Resour. Conserv. Recycl. 33, 61-74.

Pilar, L., Gonza 'lez-Torre, B., 'az, A.-D., 2005. Influence of Distance on the motivation and frequency of household recycling. Waste Manage. 25, 15-23.

Prochaska, J., Di Clemente, C., 1986. Towards a comprehensive model of change, in treating addictive behaviours: processes of change. Miller, W., Heather, N. (Eds). New York: Plenum.

Roddick, F.S.W.A.J.R.F.A., 1997. Relationships between set-out rate, participation rate and set-out 15 
quantity in recycling programs. Resour. Conserv. Recycl. 20, 1-17.

Seonaidh, Caroline, 2003. Reasons for non-participation in a kerbside recycling scheme. Resour. Conserv. Recycl. 39, 369-385.

Sidique, S.F., Lupi, F., Joshi, S.V., 2010. The effects of behavior and attitudes on drop-off recycling activities. Resour. Conserv. Recycl. 54, 163-170.

State Statistical Bureau, 2015. Chinese Statistical Yearbook, http://www.stats.gov.cn/tjsj/ndsj/2016/indexch.htm.

Tonglet, M., Phillips, P.S., Bates, M.P., 2004. Determining the drivers for householder pro-environmental behaviour: waste minimisation compared to recycling. Resour. Conserv. Recycl. 42, 27-48.

Triandis, H., 1977. Interpersonal Behaviour. Brooks/Cole, Monterey, CA.

Vringer, K., 2005. Analysis of the energy requirement for household consumption. Utrecht University.

Williams, I., Kelly, J., 2003. Green waste collection and the public's recycling behaviour in the Borough of Wyre, England. Resour. Conserv. Recycl. 38, 139-159.

Woodard R, Harder M, Bench M., 2006. Participation in curbside recycling schemes and its variation with material types. Waste Manage. 26, 914-919.

Yau, Y., 2010. Domestic waste recycling, collective action and economic incentive: The case in Hong Kong. Waste Manage. 30, 2440-2447.

Zamorano, M., Molero, E., Grindlay, A., Rodríguez, M., Hurtado, A., Calvo, F., 2009. A planning scenario for the application of geographical information systems in municipal waste collection: A case of Churriana de la Vega (Granada, Spain). Resour. Conserv. Recycl. 54, 123-133. 


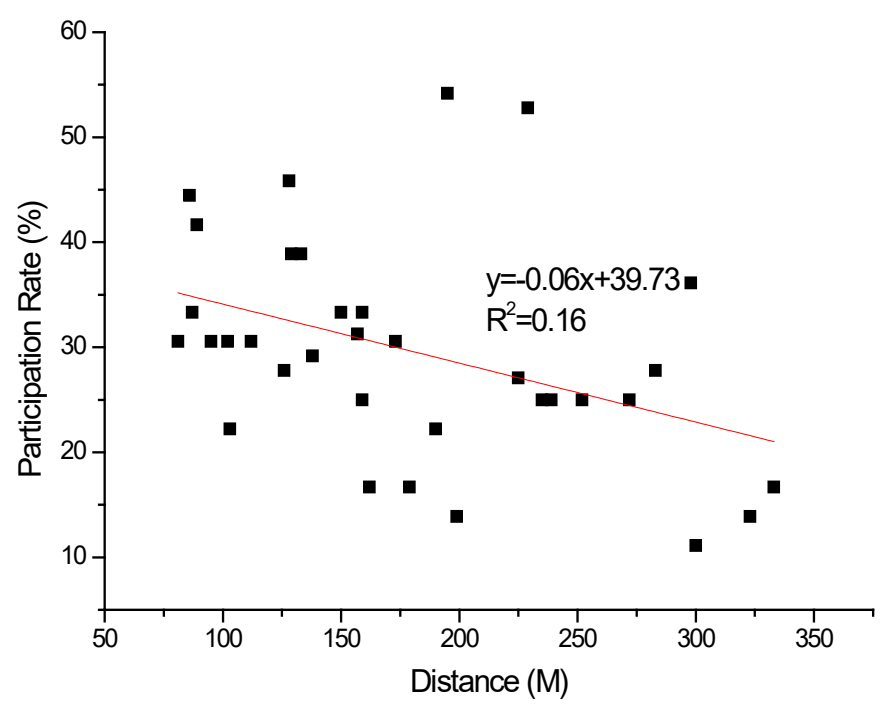

Fig.1 The relationship between Distance and the participation rate, PR, plotted by buildings in the Community. The linear regression gives a significant negative correlation indicating that the percentage of households participating in recycling in a given building decreases with Distance. 


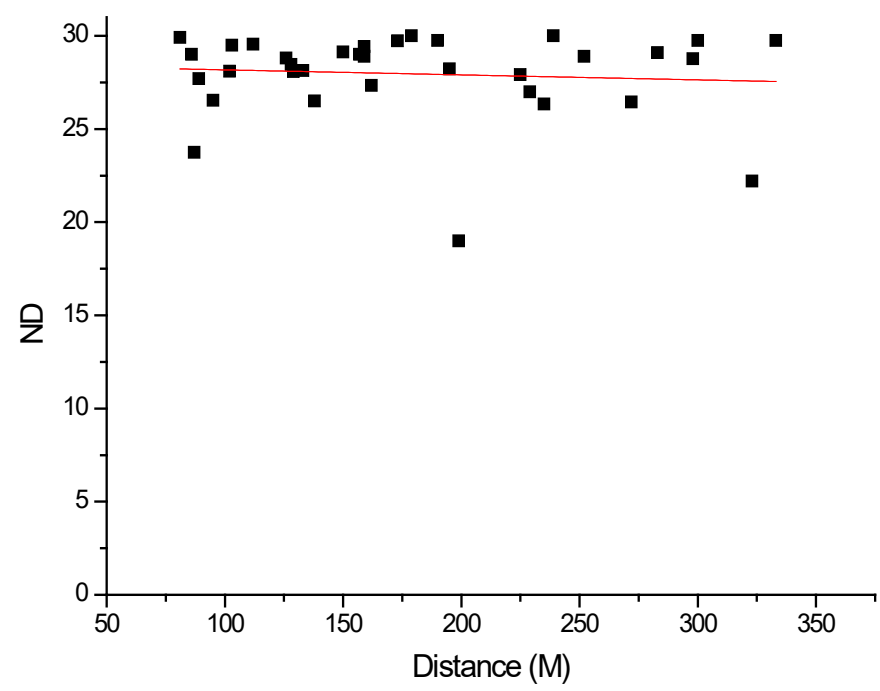

Fig. 2 The effect of Distance to frequency of participation (via proxy of number of days participated in a month, ND), in the Community. 
Table 1. Summary of all the studies found within our systematic review from 1990 to 2018 inclusive which refer to 'inconvenience' or 'distance' as potential determinants of any measured recycling performance indicator (including further works referenced therein), using Web of Science. Note that all data are Self-Reported (SR) by participants without direct measures being taken, and all models or theories where applied were done Retrospectively, not predictively.

\begin{tabular}{lccc}
\hline & Mode of measures for & & \\
Statements & Participation/Distance & Models or & Predictive or \\
& (Self-Report, Indirect & Theories & Retrospective \\
\hline
\end{tabular}

\section{Focus on convenience, not just distance}

" distance of recycling stations to have an impact on recycling participation in urban and rural areas, with an increase in participation with a decrease in distance."

" Reasons for households not recycling before the introduction of a kerbside collection scheme: the most reason is Inconvenient/no time and second most is Facilities too far away/inadequate. "

"...certain personal circumstances such as scarce availability of time and scarce availability of space in the home, and some characteristics of the selective collection system itself, such as the distance between homes and the deposit locations, make citizen participation difficult. "

" the distance between the containers was not greater than $250 \mathrm{~m}$. For organic matter and rest fractions, the residents had a container available at a distance of at least $75 \mathrm{~m}$ if not less."

\section{$\mathrm{SR} / \mathrm{SR}$}

$\mathrm{SR} / \mathrm{SR}$

$$
\text { Logistic }
$$$$
\text { regressions }
$$

Retro
(Vencatasawmy et al.,

$$
\text { 2000) }
$$

(Perrin and Barton,

$$
\text { 2001) }
$$


"positive perceptions of the convenience of recycling can have a major impact on a willingness to recycle and that these relate not only to a 'distance' factor (from one's home to a recycling point), but also the perceived storage space to keep materials and the priority of the activity in terms of time available."

" it could be seen how the SRi (Separation Rate) varied according to the distance that had to be travelled by citizens in order to deposit their waste, i.e. the lower the distance is, the higher the SRi value will be."

"The coefficients on DISTANCE imply that the expected number of visits reduces

by $1 \%$ as roundtrip distance from home to site increases by a mile."

" the presence of a kerbside system in Lithuania and a property-close collection in Sweden has a beneficial impact on recycling in each respective country if recycling convenience is increased, i.e. the household cost of recycling is decreased, then the households' reported recycling is expected to increase...."

"While most of the previous studies suggested that enhanced convenience could motivate people to recycle, putting waste separation facility on each domestic floor of building was

found to be unable to increase the average amount of recyclables.”
Fishbein and

$\mathrm{SR} / \mathrm{SR}$

Ajzen's Theory of

Retro

Reasoned Action

$\mathrm{SR} / \mathrm{SR}$

Regression models

Retro

(Gallardo et al., 2010)

$\mathrm{SR} / \mathrm{SR}$

Poisson regression

method

Retro

(Sidique et al., 2010)

ABC Hypothesis

Retro

(Miliute-Plepiene et

al., 2013)

Payoff matrix of

recycling

Retro

(Yau, 2010)

\section{Clear attempt to check recycling performance against distance}

" Results show that the people who frequently go to the bins to dispose of general refuse are more likely to recycle some product at home, and in most cases, as the distance to the recycling bins decreases, the number of fractions that citizens 
Accepted to: Waste Management (2020) 108, 183-188

"if bin distances were cut by $100 \%$ (perhaps reflecting the implementation of doorstep collection) recycling rates for containers would rise by about $66 \%$ of 
Accepted to: Waste Management (2020) 108, 183-188

Table 2. Social demographics of the Community (adapted from Li et al., 2017).

\begin{tabular}{cl}
\hline $\begin{array}{l}\text { Total Households } \\
\text { Total Residents }\end{array}$ & 1200 \\
\hline Number of buildings & 2032 \\
Age of residents & $36^{\mathrm{a}}(6$ Floors \\
each) & Number \\
0-19 & 372 \\
$50-49$ & 617 \\
$>60$ & 430 \\
Gender (Male: Female) & 613 \\
Education level of residents & Number \\
Primary School & 419 \\
Junior High School & 930 \\
High School & 673 \\
College Degree or above & 249 \\
Housing Price( RMB /m & $13000-15000$ \\
\hline
\end{tabular}

a: Two buildings (No. 23 and 27) are dormitories or basic housing for allocated workplaces, not local households, and thus not used in this study. 
Accepted to: Waste Management (2020) 108, 183-188

Table 3. Binomial logistic regression analysis of Distance related to participation rate.

Distance is given in units of $100 \mathrm{~m}$.

\begin{tabular}{|c|c|c|}
\hline & $\bar{B}$ & SE(b) \\
\hline (Intercept) & $-0.42^{*}$ & 0.17 \\
\hline Distance $(100 \mathrm{~m})$ & $-0.26 * *$ & 0.0009 \\
\hline
\end{tabular}


Accepted to: Waste Management (2020) 108, 183-188

Table 4. Binomial logistic regression analysis of Distance \& Floor related to participation rate. Distance is given in units of $100 \mathrm{~m}$.

\begin{tabular}{ccc}
\hline & $\boldsymbol{B}$ & SE $(\boldsymbol{b})$ \\
\hline (Intercept) & -0.35 & 0.22 \\
Distance (100m) & $-0.30^{* *}$ & 0.001 \\
factor(Floor)2 & 0.16 & 0.22 \\
factor(Floor)3 & 0.07 & 0.22 \\
factor(Floor)4 & -0.10 & 0.22 \\
factor(Floor)5 & -0.28 & 0.23 \\
factor(Floor)6 & -0.30 & 0.23 \\
\hline
\end{tabular}

$* \mathrm{p}<.05, * * \mathrm{p}<.01, * * * \mathrm{p}<0.001$

$B$ are the regression coefficients, $\mathrm{SE}(b)$ are the standard errors of regression coefficients 